\title{
Improper Chemical Reaction
}

National Cancer Institute

\section{Source}

National Cancer Institute. Improper Chemical Reaction. NCI Thesaurus. Code C63111.

Problem associated with an unexpected or incomplete chemical reaction or effect. 